\title{
Indicators of rational drug use and health services in Hadramout, Yemen
}

\author{
K.A. Bashrahil
}

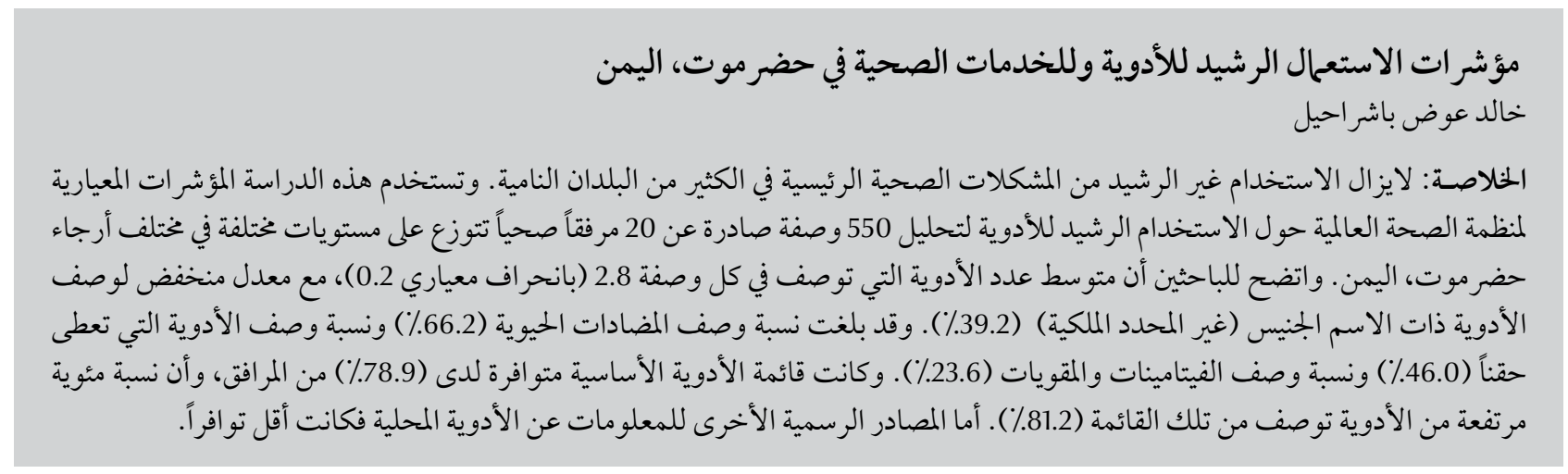

ABSTRACT The irrational use of drugs remains a key health problem in many developing countries. Using WHO standard indicators of rational drug use, this study analysed 550 prescriptions from 20 health facilities at different levels throughout Hadramout governorate, Yemen. A mean of 2.8 (SD 0.2) drugs were prescribed per prescription, with a low rate of prescribing drugs by generic name (39.2\%). The proportion of prescriptions for antibiotics was $66.2 \%$, for injectable drugs $46.0 \%$ and for vitamins/tonics $23.6 \%$. The essential drugs list was available in $78.9 \%$ of facilities and a high percentage of drugs were prescribed from the list (81.2\%). Other official sources of local drug information were less available.

\section{Indicateurs d'usage rationnel des médicaments et des services de santé dans le gouvernorat d'Hadramout (Yémen)}

RÉSUMÉ L'usage irrationnel des médicaments reste un problème de santé majeur dans de nombreux pays en développement. À l'aide des indicateurs standard de l'OMS relatifs à l'usage rationnel des médicaments, cette étude a analysé 550 ordonnances provenant de 20 établissements de santé de différents niveaux du gouvernorat d'Hadramout, au Yémen. En moyenne, 2,8 médicaments (écart type 0,2) étaient prescrits par ordonnance, avec un faible taux de prescription par nom générique (39,2\%). Les antibiotiques représentaient 66,2 \% des prescriptions, les médicaments injectables, 46,0 \% et les vitamines/fortifiants, 23,6 \%. La liste des médicaments essentiels était disponible dans 78,9\% des établissements de santé et un fort pourcentage des médicaments était prescrit à partir de la liste (81,2\%). Les autres sources officielles d'informations sur les médicaments locaux étaient moins accessibles. 


\section{Introduction}

In Yemen, as in many developing countries, inappropriate, ineffective and inefficient use of drugs is common in heath facilities at all levels $[1-5]$. There are many factors influencing irrational prescribing, e.g. patients, prescribers, the workplace environment, the supply system (including industry influences), government regulations and drug information and misinformation [6-10]. Additionally, health workers receive very little initial or continuing education about the rational use of drugs.

The concept of an essential drugs list aims to promote the rational and efficient use of drugs. First developed by the World Health Organization (WHO) in 1977, it has provided a rational basis not only for drug procurement at the national level, but also for establishing drug requirements at various levels within health care systems [6]. Essential drugs are selected to fulfil the real needs of the majority of the population in diagnostic, prophylactic, therapeutic and rehabilitative services using parameters of risk-benefit ratio, cost, effectiveness, quality and practical administration as well as patient compliance and acceptance $[6,7,11]$.

Yemen was one of the first countries in the Region to adopt an essential drugs programme in 1986, and to implement this in the public sector [12]. The first national essential drugs list (EDL) was based on the WHO list of essential drugs and other resources [13].

This study is the first to appraise the level of development of health and pharmaceutical services in Hadramout, the largest governorate in Yemen. The aim was to apply the WHO standard indicators of rational drug use to describe health workers' prescribing practices, to investigate the availability of essential drugs and local information sources, and to use the results of the study for recommending future interventions to promote the rational use of drugs.

\section{Methods}

A descriptive cross-sectional survey was carried out from December 2002 to February 2003 in 20 health facilities from different areas of Hadramout governorate. All levels of health facility, both government and private, were surveyed: 11 hospitals, 4 health centres and 5 health units (including Ibn Sina University Hospital and Hadramout University Health Centre in Mukalla, the capital city of the governorate). All suitable health facilities were surveyed, selected on the basis of their large size, easy accessibility and availability of documented prescriptions at the time of the survey.

Hospitals in Yemen deliver services to a population of around 50000 or more, with surgery, internal medicine, preventive medicine, paediatrics and maternity beds as well as diagnostic services. Health centres deliver primary health care services to the community population of around 15000 , such as mother and child services and first aid, as well as health awareness and health promotion services. Health units, with no beds, usually deliver primary health care services to a population of around 1500 .

A total of 550 prescriptions were collected randomly from the selected health facilities and examined to record information about prescribing indicators using a predesigned proforma. The number of selected prescriptions was proportional to the size of the health facility, i.e. to the number of daily outpatient visits. The standard WHO prescribing indicators were calculated:

- Mean number of drugs/prescription,

- Percentage of drugs prescribed by generic name,

- Percentage of prescriptions containing antibiotics,

- Percentage of antibiotics prescribed from all prescribed drugs,

- Percentage of prescriptions containing injectable drugs,
- Percentage of injectable drugs prescribed from all prescribed drugs,

- Percentage of prescriptions containing vitamin/tonic preparations.,

- Percentage of vitamin/tonic preparations prescribed from all prescribed drugs.

- Percentage of drugs prescribed from the national EDL.

At each health facility the following indicators were recorded:

- Availability of local drug information sources: availability of national EDL; availability of national standard treatment guidelines; and availability of the newsletter of the Supreme Board of Drugs and Medical Appliances (named Albalsem).

- Availability of 12 essential drugs chosen from the national EDL. They covered the key drugs recommended for the treatment of common health problems in the public health facilities in Hadramout.

Data are presented as simple frequency, mean and standard deviation (SD).

\section{Results}

\section{Prescribing indicators}

The 550 prescriptions were for a total of 1527 drugs, i.e. a mean of 2.8 (SD 0.2 ) drugs per prescription (range $1-10$ drugs per prescription) (Table 1). Slightly fewer drugs were prescribed per prescription in health centres [mean 2.5 (SD 0.2)] compared with health units [mean 2.8 (SD 0.2)] and hospitals [mean 2.9 (SD 0.2)].

A low percentage of drugs was prescribed by generic name in the studied health facilities (39.2\% of all prescribed drugs) (Table 2).

Antibiotics accounted for $28.8 \%$ of the total number of prescribed drugs (Table 2). The maximum number of antibiotics prescribed in any prescription was 4 . The lowest rate for prescribing 


$\begin{aligned} & \text { Table } 1 \text { Mean number of drugs prescribed per prescription in health facilities in } \\
& \text { Hadramout governorate, Yemen }\end{aligned}$
\begin{tabular}{lccc}
\hline Health facility & $\begin{array}{c}\text { No. of drugs } \\
\text { prescribed }\end{array}$ & $\begin{array}{c}\text { No. of } \\
\text { prescriptions }\end{array}$ & $\begin{array}{c}\text { Mean (SD) no. } \\
\text { of drugs per } \\
\text { prescription }\end{array}$ \\
Health units $(n=5)$ & 290 & 103 & $2.8(0.2)$ \\
Health centres $(n=4)$ & 409 & 163 & $2.5(0.2)$ \\
Hospitals $(n=11)$ & 828 & 284 & $2.9(0.2)$ \\
Total $(n=20)$ & 1527 & 550 & $2.8(0.2)$ \\
\hline
\end{tabular}

$S D=$ standard deviation .

antibiotics (26.7\%) was recorded in hospitals; $66.2 \%$ of prescriptions overall contained antibiotics (Table 3). However, the highest percentage of prescriptions containing antibiotics (68.0\%) was recorded in health units.

Injectable drugs accounted for $24.6 \%$ of total drugs prescribed (Table $2)$; the maximum number prescribed in any prescription was 5 . The lowest percentage of injectable drugs (22.2\%) was recorded for hospitals. Table 3 shows that $46.0 \%$ of total prescriptions contained injectable drugs, with the highest proportion (51.5\%) recorded in health units.

Vitamin/tonic preparations accounted for $11.2 \%$ of the total drugs prescribed (Table 2), with the maximum number prescribed in any prescription reaching 5 . These preparations were included on $23.6 \%$ of prescriptions; the highest percentage (36.9\%) was recorded for health units (Table 3 ).

Drugs from the national EDL accounted for $81.2 \%$ of those prescribed (Table 2), with the highest percentage (85.5\%) recorded for health units.

\section{Health facility indicators}

Copies of the national EDL were available in $35 \%$ of the studied health facilities (Table 4); 50\% had the national standard treatment guidelines but none had the newsletter of the Supreme Board of Drugs and Medical Appliances.

Overall, $78.8 \%$ of essential drugs were available at the studied health facilities (Table 5). The highest rate for availability of essential drugs (91.0\%) was recorded in hospitals and the lowest $(51.7 \%)$ in health units.

\section{Discussion}

In this descriptive study, the mean number of drugs per prescription was 2.8 , similar result to in the survey of Abdo-Rabbo et al. conducted in 24 health facilities from 4 different governorates in Yemen (Sana'a, Aden, Taiz and Hadramout). [10]. Polypharmacy is common in Yemen, as well as in other developing countries such as Nigeria $[12,14,15]$. This over-prescribing may lead to complexities in monitoring, confusion due to different instructions and risk of drug interactions and contraindications. One possible explanation for overprescribing is patient demand, i.e. patients prefer doctors who prescribe more drugs because they think this will ensure improvement and cure of their condition quickly [16].

There was a high rate of prescribing drugs by brand name (60.8\%), similar to Abdo-Rabbo et al.'s previous study in Yemen (68\%) [10]. It is also similar to results from a study of health units in Nepal [17]. These results may indicate a strong influence of the pharmaceutical industry on prescribers [16].

Antibiotics andinjectable drugswere also overprescribed (66.2\% and $46.0 \%$ of prescriptions respectively). Similar high rates were found by Abdo-Rabbo et al. (58\% and $37 \%$ respectively) [10], as well as in a study in Sudan [9]. The highest rates were recorded in health units, which may be due to the lower experience of prescribing by health assistants and the absence of professional doctors. The percentage of antibiotics prescribed was high (28.8\%). This is similar to previous studies in Yemen [1] and Jordan [18]. Overuse of antibiotics can lead to serious clinical problems, such as development of drug resistance, super-infection, allergies and other health hazards. The disadvantages of injections are that they are inconvenient, more expensive, less safe, painful and require skilled personnel to administer.

Vitamin/tonic preparations were frequently prescribed, as found also by Abdo-Rabbo et al. in Yemen [10]. Our field experience and observations

\begin{tabular}{|c|c|c|c|c|c|c|c|c|c|c|c|}
\hline \multirow[t]{2}{*}{ Health facility } & \multirow{2}{*}{$\begin{array}{c}\text { Total drugs } \\
\text { prescribed } \\
\text { No. }\end{array}$} & \multicolumn{2}{|c|}{$\begin{array}{l}\text { Drugs prescribed } \\
\text { by generic name }\end{array}$} & \multicolumn{2}{|c|}{ Antibiotics } & \multicolumn{2}{|c|}{ Injectable drugs } & \multicolumn{2}{|c|}{ Vitamins/tonics } & \multicolumn{2}{|c|}{$\begin{array}{l}\text { Drugs prescribed } \\
\text { from EDL }\end{array}$} \\
\hline & & No. & $\%$ & No. & $\%$ & No. & $\%$ & No. & $\%$ & No. & $\%$ \\
\hline Health units & 290 & 117 & 40.3 & 89 & 30.7 & 92 & 31.2 & 59 & 20.3 & 248 & 85.5 \\
\hline Health centres & 409 & 136 & 33.3 & 130 & 31.8 & 100 & 24.5 & 32 & 7.8 & 339 & 82.9 \\
\hline Hospitals & 828 & 345 & 41.7 & 221 & 26.7 & 184 & 22.2 & 80 & 9.7 & 653 & 78.9 \\
\hline Total & 1527 & 598 & 39.2 & 440 & 28.8 & 376 & 24.6 & 171 & 11.2 & 1240 & 81.2 \\
\hline
\end{tabular}




$\begin{aligned} & \text { Table } 3 \text { Frequency of prescriptions for antibiotics, injectable drugs and vitamins/ } \\
& \text { tonics }\end{aligned}$
\begin{tabular}{lcccccccc}
\hline Health facility & $\begin{array}{c}\text { Total } \\
\text { prescriptions }\end{array}$ & $\begin{array}{c}\text { Prescriptions for } \\
\text { antibiotics }\end{array}$ & $\begin{array}{l}\text { Prescriptions for } \\
\text { injectable }\end{array}$ & $\begin{array}{c}\text { Prugscriptions for } \\
\text { vitamins/ }\end{array}$ \\
& No. & No. & $\%$ & No. & $\%$ & No. & $\%$ \\
Health units & 103 & 70 & 68.0 & 53 & 51.5 & 38 & 36.9 \\
Health centres & 163 & 110 & 67.5 & 77 & 47.2 & 28 & 17.2 \\
Hospitals & 284 & 184 & 64.5 & 123 & 43.3 & 64 & 22.5 \\
Total & 550 & 364 & 66.2 & 253 & 46.0 & 130 & 23.6 \\
\hline
\end{tabular}

\begin{tabular}{|c|c|c|c|c|}
\hline Local drugs information available & $\begin{array}{c}\text { Health } \\
\text { units } \\
(n=5) \\
\%\end{array}$ & $\begin{array}{c}\text { Health } \\
\text { centres } \\
(n=4) \\
\%\end{array}$ & $\begin{array}{c}\text { Hospitals } \\
\qquad(n=11) \\
\%\end{array}$ & $\begin{array}{c}\text { Total } \\
(n=20) \\
\%\end{array}$ \\
\hline National EDL & 40 & 0 & 45 & 35 \\
\hline $\begin{array}{l}\text { National standard treatment } \\
\text { guidelines }\end{array}$ & 60 & 25 & 55 & 50 \\
\hline $\begin{array}{l}\text { Newsletter of Supreme Board of } \\
\text { Drugs and Medical Appliances }\end{array}$ & 0 & 0 & 0 & 0 \\
\hline
\end{tabular}

$E D L=$ essential drugs list.

\begin{tabular}{lcccc}
\hline Table 5 Availability of essential drugs at different levels of health facility & \\
\hline Essential drugs available & $\begin{array}{c}\text { Health units } \\
(n=5)\end{array}$ & $\begin{array}{c}\text { Health } \\
\text { centres } \\
(n=4)\end{array}$ & $\begin{array}{c}\text { Hospitals } \\
(n=11)\end{array}$ & $\begin{array}{c}\text { Total } \\
(n=20)\end{array}$ \\
Oral rehydration solution & 100 & 100 & 100 & 100 \\
Co-trimoxazole & 60 & 100 & 100 & 90 \\
Paracetamol paediatric syrup & 40 & 100 & 82 & 75 \\
Chloroquine & 60 & 75 & 100 & 85 \\
Ferrous sulfate + folic acid & 40 & 100 & 91 & 80 \\
Tetracycline eye ointment & 40 & 75 & 91 & 75 \\
lodine & 60 & 75 & 91 & 80 \\
Gentian violet & 60 & 75 & 100 & 85 \\
Benzoic acid + salicylic acid & 0 & 50 & 64 & 45 \\
Retinol (vitamin A) & 20 & 50 & 73 & 55 \\
Paracetamol or aspirin & 60 & 75 & 100 & 85 \\
Aluminium/magnesium hydroxide & 80 & 75 & 100 & 90 \\
Mean & 51.7 & 79.2 & 91.0 & 78.8 \\
\hline
\end{tabular}

suggest this may be due to the belief among many patients and some prescribers that they are useful to improve general health and quality of life.

We found a much higher proportion of drugs were prescribed from the national EDL in our study (81.2\%) than in Abdo-Rabbo et al.'s previous and the Supreme Board of Drugs and Medical Appliances newsletter were $50 \%$ and $0 \%$ respectively. These results were better than those of Abdo-Rabbo et al. for the different governorates of Yemen, where the availability of national standard treatment guidelines at that time was $2 \%$, and availability of the drugs newsletter was $0 \%[10]$. The increase in the availability of the EDL (35\%) as compared with the previous study (5\%) [4] and the higher proportion of drugs prescribed from the EDL was probably due to the increased availability of essential drugs (78.8\%) at health facilities compared with the above-mentioned study (47\%). There was progress in the prescribing rationality and availability of essential medicines compared with previous studies conducted in Yemen.

\section{Recommendations}

Prescribers in all health facilities should be advised to use the generic names of drugs in prescriptions, to prescribe the lowest number of drugs needed and to avoid symptomatic treatment whenever possible. Antibiotics and injectable drugs should be prescribed with care. More effort is needed to ensure that local drug information resources such as national standard treatment guidelines and the national formulary of essential drugs are available at all health facilities.

The Ministry of Public Health and Population should supervise, monitor, and give feedback to health workers, by developing and implementing interventions about drug use in general and prescribing in particular in order to improve prescribing practices and rational use of drugs. there is still room for improvement: the national EDL provides prescribers with a standard list of drugs which are effective, safe, inexpensive and specific in treating important health problems in our country [19]. The availability of the national standard treatment guidelines

\section{Acknowledgements}

Wewould like toexpress ourgratitudeand appreciation to our collegue Dr Ahmed Abdo-Rabbo, Professor of Pharmacology 
and Therapeutics, who fully supported this study and provided input.

Our sincere thanks and gratitude go to the 10 third year medical students who assisted in collecting data: Abdulaziz
Alahmadi, KhalidAlNahdi, Aws Hameed Swadi, Nasser M. Salah, Waleed Swaidan, Mohammed Bazmool,Tariq Mussaied,Omar Mattar, Nabeel BinSaleh and Adel Al-Amri. Due thanks and gratitude to collegues, staff members in the Faculty of Medicine, University of Hadramout for Science and Technology and to the Department of Community Medicine for their support.

\section{References}

1. Abdo-Rabbo A, Haaijer-Ruskamp F, Bashrahil K. Baseline prescribing and health facility indicators in Yemen. Journal of the Faculty of Medicine, Baghdad, 2000, 42(4):824-9.

2. Abdo-Rabbo A. Patients' care regarding consultation and dispensing in some of the public hospitals and private clinics in Sana'a. INRUD news, 1995, 2(5):22-3.

3. Abdo-Rabbo A. Doctors' prescribing practices in hospital outpatient departments in Aden. University of Aden journal of natural and applied sciences, 1997, 1(2):22-3.

4. Laing RO. Promoting rational drug use. Contact, 1994, October:1-6.

5. Quick J, Laing R, Ross-Degnan D. Intervention research to promote clinically effective and economically efficient use of pharmaceuticals: the International Network for Rational Use of Drugs. Journal of clinical epidemiology, 1991. 44(2):57S-65S.

6. The use of essential drugs. Model list of essential drugs (seventh list). Fifth report of the WHO Expert Committee. Geneva, World Health Organization, 1992:3-10.

7. Van der Geest S, Hardon A, Whyte SR. Planning for essential drugs: are we missing the cultural dimension? Health policy and planning, 1990, 5(2):182-5.

8. Hogerzeil HV. Promoting rational prescribing: an international perspective. British journal of clinical pharmacology, 1995, 39:1-6.

9. Sachs L, Tomson G. Medicines and culture-a double perspective on drug utilization in developing country. Social science \& medicine, 1992, 34(3):307-15.
10. Abdo-Rabbo A, Haaijer-Ruskamp FM, Basharahil KA. Baseline prescribing and health facility indicators in Yemen. Journal of the Faculty of Medicine, Baghdad, 2000, 42(4):824-9.

11. Budon-Jakobowicz P. WHO action program on essential drugs: what does it do? Contact, 1994, October:17-8.

12. Hogerzeil HV et al. Impact of an essential drug programme on the availability and rational use of drugs. Lancet, 1989, 333:141-2.

13. National essential drug list. General Directorate of Pharmaceutical Services and Medical Supplies. Sana'a, Yemen, Ministry of Public Health, 1996.

14. Ross Deynan $D$ et al. Field tests for rational drug use in twelve developing countries. Lancet, 1993, 342:1408-10.

15. Bimo. Report on Nigeria field test. INRUD news, 1992, 3(1):910.

16. Soumerai S. Factors influencing prescribing. Australian journal of hospital pharmacy, 1988, 18(Suppl.):9-16.

17. Kafle KK and members of INRUD Nepal Core Group. INRUD drug use indicators in Nepal practice patterns in health posts in four districts. INRUD news, 1993, 3(1):15.

18. Otoom $\mathrm{S}$ et al. Evaluation of drug use in Jordan using WHO prescribing indicators. Eastern Mediterranean health journal, 2002, 8(4/5):537-43.

19. Yemen treatment guidelines and essential drug list. Sana'a, Yemen, Pharmacy Sector, Ministry of Public Health and Population, 2001.

\section{Pan Arab Conference on Diabetes (PACD 14): Cardiometabolic Risk Initiative}

Cardiometabolic Risk Initiative is the main theme of the Pan Arab Conference on Diabetes, to be held in Cairo, Egypt on 23-26 March 2010.

The objective is to gather together all those interested in this area of medical knowledge so that they can share new insights and thus contribute to improving the care of patients, which is our primary mission. Experts from different countries will exchange their experiences in the field of diabetes. Recent advances in population studies and clinical and basic research will be presented. International scientists will give state-of-the-art lectures. Several sessions will be devoted to presentations of original contributions and a number of satellite symposia will be held during the conference. The programme can be accessed at: http://www.arab-diabetes.com. 